\title{
A democratização do acesso à água em regiões semiáridas e a importância da Lei
}

\section{$12.873 / 2013$}

The democratization of access to water in semiarid regions and the importance of Law 12,873/2013

La democratización del acceso al agua en las regiones semiáridas y la importancia de la Ley

\section{$12.873 / 2013$}

Recebido: 23/08/2021 | Revisado: 28/08/2021 | Aceito: 01/09/2021 | Publicado: 04/09/2021

\author{
Amanda Cristiane Gonçalves Fernandes \\ ORCID: https://orcid.org/0000-0001-8462-6171 \\ Universidade Federal de Campina Grande, Brasil \\ E-mail: amandafernandestt@gmail.com \\ Igo Marinho Serafim Borges \\ ORCID: https://orcid.org/0000-0002-3662-1859 \\ Universidade Federal de Campina Grande, Brasil \\ E-mail: igomarinho27@gmail.com \\ Viviane Farias Silva \\ ORCID: https://orcid.org/0000-0002-5891-0328 \\ Universidade Federal de Campina Grande, Brasil \\ E-mail: viviane.farias@professor.ufcg.edu.br \\ Ramon Marinho Gomes \\ ORCID: https://orcid.org/0000-0001-8382-8628 \\ Universidade Estadual da Paraíba, Brasil \\ E-mail: ramongomes032@gmail.com
}

\begin{abstract}
Resumo
Com o advento da Lei das Águas as entidades públicas passaram a ter um olhar mais abrangente sobre os recursos hídricos. A gestão hídrica passou a conciliar com as questões ambientais. Este estudo foi realizado objetivando-se analisar os avanços legais decorrentes das ações de democratização do acesso à água em região com déficit hídrico, como o semiárido. Para a concretização deste estudo, utilizou-se a metodologia de pesquisa dedutiva e investigativa, de cunho bibliográfico, exploratório e descritivo. Apesar da sociedade brasileira em seus diversos setores estarem integrados no planejamento de ações voltadas para a sustentabilidade e democratização dos recursos naturais, colocando em prática as legislações nacionais, é fundamental que ocorra uma conscientização em massa e intensa para que a população brasileira reivindique dos seus representantes a elaboração de leis que auxiliem na execução de políticas públicas que assegurem uma melhoria na qualidade de vida e um espaço ecologicamente equilibrado e sustentável.
\end{abstract}

Palavras-chave: Lei das águas; Recursos hídricos; Déficit hídrico; Sustentabilidade.

\begin{abstract}
With the advent of the Water Law, public entities began to have a more comprehensive look at water resources. Water management began to reconcile with environmental issues. This study was carried out with the aim of analyzing the legal advances resulting from actions to democratize access to water in a region with a water deficit, such as the semiarid region. To carry out this study, the methodology of deductive and investigative research was used, with a bibliographic, exploratory and descriptive nature. Although Brazilian society in its various sectors is integrated in the planning of actions aimed at the sustainability and democratization of natural resources, putting national legislation into practice, it is essential that massive and intense awareness occurs for the Brazilian population to claim its representatives the elaboration of laws that assist in the execution of public policies that ensure an improvement in the quality of life and an ecologically balanced and sustainable space.
\end{abstract}

Keywords: Law of waters; Water resources; Water deficit; Sustainability.

\section{Resumen}

Con la llegada de la Ley de Aguas, las entidades públicas comenzaron a tener una visión más integral de los recursos hídricos. La gestión del agua comenzó a reconciliarse con los problemas ambientales. Este estudio se realizó con el objetivo de analizar los avances legales resultantes de acciones para democratizar el acceso al agua en una región con déficit hídrico, como es el semiárido. Para la realización de este estudio se utilizó la metodología de investigación deductiva e investigativa, con carácter bibliográfico, exploratorio y descriptivo. Si bien la sociedad brasileña en sus diversos sectores está integrada en la planificación de acciones encaminadas a la sostenibilidad y democratización de los recursos naturales, poniendo en práctica la legislación nacional, es fundamental que se produzca una conciencia 
masiva e intensa para que la población brasileña pueda reclamar a sus representantes la elaboración. de leyes que coadyuven en la ejecución de políticas públicas que aseguren una mejora en la calidad de vida y un espacio ecológicamente equilibrado y sostenible.

Palabras clave: Ley de aguas; Recursos hídricos; Déficit de agua; Sustentabilidad.

\section{Introdução}

Com o advento da Lei das Águas (Lei 9.433/1997) as entidades públicas passaram a ter um olhar mais abrangente sobre os recursos hídricos. A gestão hídrica passou a conciliar com as questões ambientais. Além disso, a descentralização das ações de gerenciamento passou a ser uma construção coletiva com a inserção de vários autores.

Nessa perspectiva, as leis que regem as ações de gestão e gerenciamento dos recursos hídricos estão sendo criadas com a perspectiva de democratizar o acesso a água como garantia da vida, da qualidade de vida e desenvolvimento sustentável em regiões com déficits hídricos e comunidades rurais carentes.

Uma das características principais do semiárido brasileiro é a variabilidade climática e a escassez de água. Apesar do déficit hídrico possui um índice pluviométrico entre 200 e $800 \mathrm{~mm}$ ao ano, distribuído irregularmente no tempo e no espaço (IBGE, 2010; Cavenaghi \& Silva 2016).

A implantação do Programa Cisternas nasceu sob a perspectiva de um marco teórico com a necessidade de uma gestão democrática a partir da criação da Lei 12.873/2013 e trata-se de um novo paradigma para a convivência com a seca. A necessidade de leis que sejam sancionadas que potencializem a gestão democrática dos recursos hídricos é imprescindível para assegurar a qualidade de vida das famílias agricultoras e o desenvolvimento local.

Uma abordagem sistêmica do semiárido brasileiro possibilita a compreensão das dimensões geofísica, social, econômica, política e cultural. No que se refere à necessidade e possibilidade de convivência com os ecossistemas frágeis, a construção da sustentabilidade depende de um processo participativo da população local no resgate e construção cultural de alternativas apropriadas aos ecossistemas (Silva, 2003).

Estabelecimento de um aproveitamento racional e ecologicamente sustentável da natureza em benefício das populações locais, levando-as a incorporar a preocupação com a conservação da biodiversidade aos seus próprios interesses, como um componente da estratégia de desenvolvimento (Sachs, 1986).

Para a concretização deste estudo, utilizou-se a metodologia de pesquisa dedutiva e investigativa, de cunho bibliográfico, exploratório e descritivo. Em se tratando de pesquisa dedutiva, entende-se que neste tipo de estudo, as conclusões encontram-se implícitas nas suas premissas (Santos et al., 2018). A pesquisa bibliográfica é desenvolvida a partir de material já elaborado, constituído principalmente de livros, artigos científicos e leis.

Em se tratando de pesquisa descritiva, tem-se que está se caracteriza por descrever fatos que ocorrem no cotidiano do pesquisador, porém não possuem aprofundamento científico necessário para que todas as suas hipóteses sejam solucionadas. (Gil, 1999). No que tange a metodologia investigativa, tem-se que esta pode ser utilizada como um processo orientado que conduz o pesquisador a situações capazes de despertar a necessidade e o prazer pela descoberta do conhecimento (Silva et al., 2016). A metodologia aplicada quanto à abordagem do problema é também de cunho qualitativa "A pesquisa qualitativa preocupa-se com a compreensão, com a interpretação do fenômeno, considerando o significado que os outros dão as suas práticas, o que impõe ao pesquisador uma abordagem hermenêutica". (Gonsalves, 2011).

Nesse contexto, esta pesquisa foi realizada objetivando-se analisar os avanços legais decorrentes das ações de democratização do acesso à água em região com déficit hídrico. Como objetivos específicos, tem-se: Analisar a legislação vigente sobre a temática de gestão/gerenciamento dos recursos hídricos; Verificar como se dá a aplicação da democratização do acesso à água no semiárido paraibano e as ações de políticas públicas. 


\section{Metodologia}

A metodologia aplicada quanto à abordagem do problema será qualitativa, uma vez que a pesquisa se ocupa em descrever as características que evidenciam a importância da Lei 12.873/2013. "A pesquisa qualitativa preocupa-se com a compreensão, com a interpretação do fenômeno, considerando o significado que os outros dão as suas práticas, o que impõe ao pesquisador uma abordagem hermenêutica". (Gonsalves, 2011). Além disso, conta-se com a metodologia dedutiva e investigativa, de cunho bibliográfico, exploratório e descritivo. Em se tratando de pesquisa dedutiva, entende-se que neste tipo de estudo, as conclusões encontram-se implícitas nas suas premissas (Santos et al., 2018). A pesquisa bibliográfica é desenvolvida a partir de material já elaborado, constituído principalmente de livros, artigos científicos e leis.

Nesse contexto, na pesquisa qualitativa o pesquisador com conjunto de materiais disponível tem um entendimento amplo de seu problema. Quanto ao objetivo será descritiva, pois a pesquisa visa descrever detalhadamente os avanços legais decorrentes das ações de democratização do acesso à água em regiões com déficits hídricos. "A pesquisa descritiva objetiva escrever as características de um objeto estudado (...). Nesse caso, a pesquisa não está interessada no porquê, nas fontes do fenômeno; preocupa-se em apresentar suas características". (Gonsalves, 2011).

Assim, a pesquisa descritiva descreve as características e exige um comportamento próprio afastando as ideias gerais. Quanto aos procedimentos técnicos apresentamos como uma pesquisa bibliográfica, uma vez que indicamos os posicionamentos doutrinários e jurisprudenciais sobre o tema. "Pesquisa bibliográfica é desenvolvida a partir de material já elaborado, constituído principalmente de livros e artigos científicos". (Gil, 2000). Dessa forma, a pesquisa é bibliográfica, uma vez que utilizamos para desenvolvê-la livros impressos e eletrônicos.

\section{Desenvolvimento}

\subsection{O semiárido brasileiro e a convivência com a seca}

A intervenção do Estado Brasileiro na região Nordeste sempre foi marcada pela centralização e fragmentação de suas ações e políticas públicas, se concretizando pela criação de organismos de "luta" contra a seca (Passador et al., 2010). Ao longo da história de formação territorial do semiárido nordestino, foram criados diversos órgãos como a Inspetoria de Obras Contra a Seca (IOCS), a Inspetoria Federal de Obras Contra as Secas (IFOCS) e o Departamento Nacional de Obras Contra as Secas (DNOCS) (Araújo et al., 2015).

As entidades políticas vêm apoiando novas formas de enfrentar o problema das secas e a falta de acesso as águas no semiárido com o uso de tecnologias sociais através do Programa de Cisternas, como: Programa Um Milhão de Cisternas (P1MC) e o Programa Uma Terra Duas Águas (P1+2) (Araújo et al., 2015).

No semiárido brasileiro a massificação da cisterna como solução para o acesso das famílias à água captada da chuva é uma realidade. Atualmente são 479.595.000 mil cisternas construídas pelo Programa Um Milhão de Cisternas - P1MC5 (ASA/Brasil, 2004; Costa, 2013).

\subsection{A política nacional de recursos hídricos para o acesso à água.}

No dia 8 de janeiro de 1997 foi criada a Lei 9.433 conhecida como a "Lei das Águas". A partir disso, também foi instituída a Política Nacional de Recursos Hídricos (PNRH) e o Sistema Nacional de Gerenciamento de Recursos Hídricos (Singreh). Anteriormente a esta lei, a gestão das águas era regida pelo Código das Águas de 1934.

Os principais avanços sobre a criação da Lei 9.433 foram: a gestão integrada dos recursos hídricos e o meio ambiente buscando um equilíbrio ecológico e sustentável, a gestão descentralizada buscando a participação de diversos autores conforme aponta em seu art. $1^{\circ}$, vi- "a gestão dos recursos hídricos deve ser descentralizada e contar com a participação do Poder Público, dos usuários e das comunidades". 
A gestão descentralizada possibilita ações mais efetivas sobre a democratização do acesso à água em regiões que sofrem com escassez hídrica. Os diferentes autores envolvidos podem discutir juntos as melhores ações sobre o gerenciamento das águas e estratégias para o enfrentamento nos períodos de seca. Na região do semiárido brasileiro, por exemplo, os efeitos da "Indústria da Seca" acumularam durante décadas a inviabilidade efetiva de ações de desenvolvimento local. Segundo (Silva, 2003):

"De modo geral, as ações governamentais de intervenção nessa realidade foram sendo construídas com base nas seguintes características: a) o caráter emergencial, fragmentado e descontínuo dos programas desenvolvidos em momentos de calamidade pública; b) as ações emergenciais que alimentam a "indústria da seca"; e, c) a solução hidráulica, com a construção de obras hídricas, quase sempre favorecendo empreiteiras e a grande propriedade rural. Em todas essas características reproduz-se o uso político do discurso da miséria e do subdesenvolvimento como decorrência direta das secas".

Mesmo com a expansão da política de Açudagem no Nordeste não foi possível resolver os problemas de uso e acesso à água. Havia muita perca d'água por evaporação e problemas nas funcionalidades dos açudes. Aziz Ab’Sáber (1999) indica outras problemáticas encontradas na implementação dos grandes açudes que não alcançaram seus objetivos, principalmente, na parte agrícola. Alguns estavam localizados longe de várzeas irrigáveis e os que favoreciam a distribuição de água por gravidade para áreas irrigáveis atendiam a um número limitado de famílias (Lima, 2018).

Com o advento da "Lei das Águas" possibilitou-se uma maior abrangência de articulação entre os entes políticos como expresso no art.3, iv- "a articulação do planejamento de recursos hídricos com o dos setores usuários e com os planejamentos regional, estadual e nacional."

Além disso, um marco importante foi uma visão mais global sobre as questões ambientais integrando a gestão dos recursos hídricos com o meio ambiente para garantir à manutenção do meio ecologicamente equilibrado e o desenvolvimento sustentável. Conforme consta uma das diretrizes gerais de ação para implementação da PNRH em seu art.3, iii-“a integração da gestão de recursos hídricos com a gestão ambiental”.

\subsection{Lei 12.873/2013-programa nacional de apoio à captação de água de chuva e outras}

\subsubsection{Tecnologias de acesso à água}

A Lei 12.873/2013 institui o Programa Nacional de Apoio à Captação de Água de Chuva e Outras Tecnologias Sociais de Acesso à Água através do Programa Cisternas. Em seu art.11 da referida lei é possível observamos suas finalidades visando a promoção de garantias fundamentais para a vida como o direito a água e a segurança alimentar.

Art. 11. Fica instituído o Programa Nacional de Apoio à Captação de Água de Chuva e Outras Tecnologias Sociais de Acesso à Água - Programa Cisternas, com a finalidade de promover o acesso à água para o consumo humano e animal e para a produção de alimentos, por meio de implementação de tecnologias sociais, destinado às famílias rurais de baixa renda atingidas pela seca ou falta regular de água.

O Programa Cisternas surgiu com a finalidade de política pública sendo financiado pelo extinto Ministério do Desenvolvimento Social (atualmente substituído pelo Ministério das Cidades) desde 2003 e tinha como objetivo a promoção do acesso à água para o consumo humano e para a produção de alimentos por meio da implementação de tecnologias sociais simples e de baixo custo. O público alvo do programa eram famílias rurais de baixa renda atingidas pela seca ou invariabilidade de precipitação. Para participarem, as famílias devem necessariamente estar inscritas no Cadastro Único para Programas Sociais do Governo Federal. 
O semiárido brasileiro é a região prioritária do programa para a implementação dessas cisternas. O programa estava voltado em promover para as famílias rurais a convivência com a escassez de chuva e o desenvolvimento de práticas agroecológicas utilizando principalmente a tecnologia de cisternas de placas, reservatórios que armazenam água de chuva para utilização no período de 6 a 8 meses para uma família de até 5 pessoas e em período mais crítico de estiagem dessa região.

De acordo com a Secretaria Especial do Desenvolvimento Social (2021) os tipos de cisternas implementados pelo Programa Cisternas:

- Cisterna familiar de água para consumo, instaladas ao lado das casas e com capacidade de armazenar 16 mil litros de água potável.

- Cisterna Escolar de água para consumo, instaladas em escolas do meio rural e com capacidade de armazenar 52 mil litros de água potável.

- Cisterna de água para produção, com capacidade de 52 mil litros de água, de uso individual ou coletivo das famílias.

A implementação das ações referente ao Programa Cisternas é um exemplo sobre a democratização do acesso à agua e a descentralização no gerenciamento dos recursos hídricos. Todos os entes políticos, organizações não governamentais e a sociedade civil como autores na implementação dessas ações, conforme conta no art.12 da referida lei.

Art. 12. No âmbito do Programa Cisternas, a União, por intermédio do Ministério do Desenvolvimento Social e Combate à Fome, poderá firmar parceria com os Estados, o Distrito Federal, os Municípios, os consórcios públicos constituídos como associação pública e as entidades privadas sem fins lucrativos, inclusive aquelas qualificadas como Organização da Sociedade Civil de Interesse Público, observado o disposto no art. 116 da Lei no 8.666, de 21 de junho de 1993.

Ressalta-se que em 30 de outubro de 2017 foi criada a Lei 13.501 altera o art. $2^{\circ}$ da Lei $n^{\circ} 9.433$, de 8 de janeiro de 1997, que institui a Política Nacional de Recursos Hídricos, para incluir o aproveitamento de águas pluviais como um de seus objetivos. O caput do art. $2^{\circ}$ da Lei $n^{\circ} 9.433$ passa a vigorar acrescido do seguinte inciso IV: "incentivar e promover a captação, a preservação e o aproveitamento de águas pluviais".

\subsubsection{Decreto $N^{\circ}$ 9.606/2018.}

O Programa Nacional de Apoio à Captação de Água de Chuva e Outras Tecnologias Sociais de Acesso à Água instituído pela Lei $\mathrm{n}^{\circ}$ 12.783, de 24 de outubro de 2013, será regido por este Decreto ${ }^{\circ} 9.606$ estabelecido em 10 de dezembro de 2018 e por disposições complementares estabelecidas em atos do Ministério do Desenvolvimento Social.

O objetivo é promover o acesso à água para o consumo humano e animal e para a produção de alimentos, por meio de implementação de tecnologias sociais, destinado a famílias rurais de baixa renda e equipamentos públicos rurais atingidos pela seca ou pela falta regular de água.

De acordo com o art.2, parágrafo único, para fins do disposto neste decreto, considera-se:

I - família de baixa renda - aquela definida nos incisos I e II do caput do art. $4^{\circ}$ do Decreto $n^{\circ} 6.135$, de 26 de junho de 2007;

II - equipamento público - instalação ou espaço de infraestrutura destinado aos serviços públicos de educação, saúde, assistência social e congêneres;

III - zona rural - área que abrange qualquer domicílio isolado ou em aglomerado que não esteja localizado em sede de Município ou em perímetro urbano;

IV - falta regular de água - falta de acesso à água em quantidade ou qualidade suficientes para o consumo humano ou para a produção de alimentos; 
V - tecnologia social de acesso à água - conjunto de técnicas e de métodos aplicados para a captação, o armazenamento, o uso e a gestão da água, desenvolvidos a partir da interação entre o conhecimento local e técnico, apropriados e implementados com a participação da comunidade; e

VI - SIG Cisternas - sistema informatizado utilizado no âmbito do Programa Cisternas para o registro de informações sobre as atividades associadas à implementação das tecnologias sociais de acesso à água, sem prejuízo do disposto no parágrafo único do art. 13.

O decreto complementa as temáticas referentes as formas de execução do Programa de Cisternas, liberação de recursos, credenciamento de entidades privadas sem fins lucrativos, edital de chamada pública para a seleção das entidades privadas sem fins lucrativos, a implementação e entrega das tecnologias sociais hídricas, além da fiscalização, transparência e controle social (Paula, 2012).

\subsection{O uso das tecnologias sociais e o desenvolvimento rural no semiárido paraibano}

Essas Tecnologias Sociais tem o objetivo de realizar mudanças nas estruturas sociais das populações do semiárido, tendo como base um processo simples de captação e armazenamento de água da chuva, visando o abastecimento de residências no período de estiagem (Coutinho, 2010).

A vantagem dessas tecnologias é que elas são muito baratas, chegam na ponta e permitem um aproveitamento minucioso da água e dos solos. Não havendo desperdício nem agressão ao meio ambiente. (Malvezzi, 2007). O programa tem como objetivo, garantir água de boa qualidade, gerando um uso racional desse recurso de tal modo que sua escassez relativa não continue a constituir impedimento ao desenvolvimento sustentável da região (Costa, 2013).

Outro ponto importante do programa é a capacitação da população, a qual passa a ter o domínio necessário da técnica para captação e armazenamento da água. Fazendo com que a qualidade da alimentação e da água melhora, com desdobramentos positivos na saúde e na renda (Malvezzi, 2007).

Nos assentamentos da Paraíba há famílias que, ao utilizarem essas tecnologias e práticas agrícolas garantem sua alimentação e obtêm uma renda muito superior a qualquer programa assistencial do governo (Lima, 2018). Além do mais, se ganha em cidadania, já que as pessoas passam a viver do fruto do seu trabalho e não de ajudas. Há ainda o fator ambiental: evitam-se as pragas e a salinização dos solos, que tornam inviável a atividade da irrigação em muitos projetos. (Malvezzi, 2007).

Na (Figura 1) cisterna localizada no assentamento São Domingos no município de Cubati-PB, onde tem como principal função a captação e o armazenamento da água de chuva para as necessidades domésticas. Trata-se de uma cisterna de placa de cimento com capacidade para 16 mil litros de água e que sendo usada para os seus devidos fins (água de beber e cozinhar) consegue assegurar esse recurso por até oito meses para uma família com até cinco pessoas (ASA Brasil, 2019). 
Figura 1: Cisterna usada na captação da água da chuva no assentamento São Domingos no município de Cubati - PB.

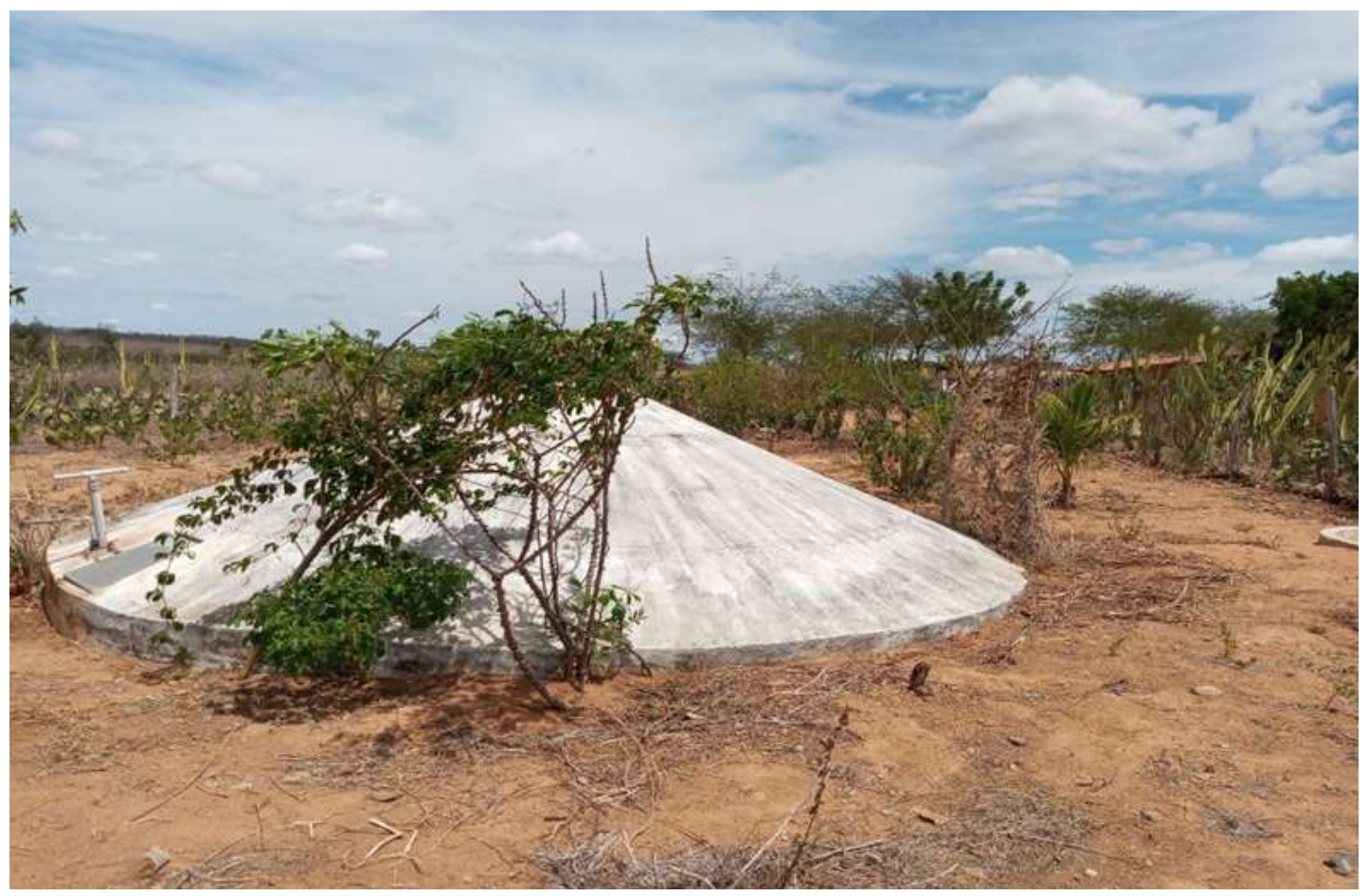

Fonte: Autores (2021).

As cisternas são fundamentais para a convivência com o semiárido, democratização do recurso natural (água) e para a garantia da vida. Sem a água o direito à vida presente no art. 5 Constituição Federal de 1988 estaria veemente ameaçado

\subsubsection{Polo da Borborema: um dos principais atores na gestão participativa para o desenvolvimento rural no} semiárido paraibano

O Polo da Borborema, corresponde a uma articulação de sindicatos rurais e organizações de apoio à agricultura familiar no território da Borborema, na Paraíba. Uma das características fundamentais desse território foi existência prévia de uma articulação regional (um “território”), distinguida por forte presença da sociedade civil com grande capacidade de ação coletiva e de iniciativas locais (Diniz, 2007). A Figura 2 mostra o mapa político dos municípios que estão inseridos no semiárido paraibano e que fazem parte do Polo da Borborema. 
Figura 2: Mapa Político do Polo da Borborema.

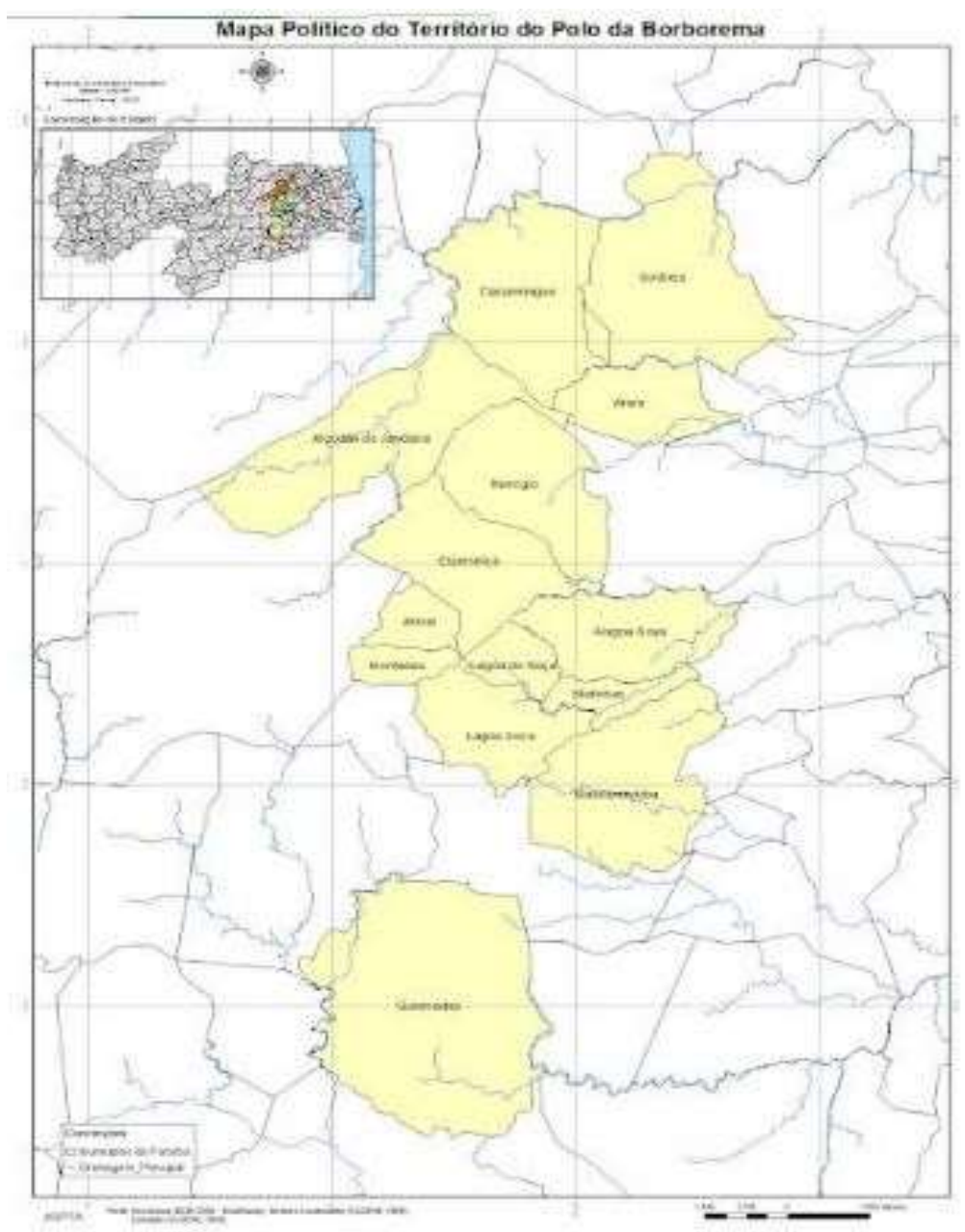

Fonte: ASPTA (2014).

Os municípios que compreendem o Polo da Borborema são: Casserengue, Solânea, Arara, Algodão de Jandaíra, Remígio, Esperança, Areial, Montadas, Alagoa Nova, Lagoa de Roça, Lagoa Seca, Matinhas, Massaranduba e Queimadas.

Formado por uma rede de 15 sindicatos de trabalhadoras e trabalhadores rurais (STRs), aproximadamente 150 associações comunitárias e uma organização regional de agricultores ecológicos, o Polo da Borborema vem apoiando redes locais de inovação agroecológica que articulam mais de 5 mil famílias agricultoras dos 15 municípios que conformam o Território da Borborema (Silveira, Freire \& Diniz, 2010).

O Território da Borborema teve sua homologação realizada em 29 de julho de 2003, após a constituição do Programa dos Territórios Rurais de Identidade da Secretaria de Desenvolvimento Territorial e Ministério do Desenvolvimento Agrário (SDT/MDA).

Primeiro, o território SDT inclui o município urbano de Campina Grande e, segundo seu espaço geográfico é contínuo, seguindo as normas estabelecidas pela SDT. Os municípios do território da SDT que não participam do Pólo Sindical são os municípios de atuação do Fórum dos Assentados da Reforma Agrária (Borborema, Serrania, Pilões, Areia), localizados ao leste do território do Pólo Sindical, assim como alguns municípios isolados, localizados no Sudeste (Serra Redonda), no Oeste (Puxinanã) e no Noroeste (Algodão de Jandaíra) (Piraux \& Bonnal, 2007).

Os municípios localizados na parte ocidental do "território" do Pólo Sindical não foram incorporados no território da SDT da Borborema, mas sim no território da SDT do Cariri (Piraux \& Bonnal, 2007). 
Analisando a partir de seu lugar na história do território poderíamos dizer que o Polo retoma e atualiza uma longa tradição de resistências sociais que aí se estruturaram como respostas ativas a conjunturas políticas e econômicas adversas à agricultura camponesa (Silveira; Freire \& Diniz, 2010).

\section{Conclusão}

Nesse sentido, o nosso estudo conseguiu analisar as leis que regem a gestão/gerenciamento dos recursos hídricos com os avanços de uma percepção mais participativa e democrática do acesso ao recurso natural que é a água. Além disso, é importante que sejam criados e sancionados projetos de leis que viabilizem as políticas públicas como, por exemplo, a das tecnologias sociais (Projeto de Lei do Senado $N^{\circ} 111$ ) que institui a Política Nacional de Tecnologia Social de autoria do Senador Rodrigo Rollemberg (PSB/DF) em 2011 e que passou por uma tramitação bicameral sendo aprovada e aguarda que seja sancionada como lei.

Conclui-se, portanto, que apesar de a sociedade brasileira em seus diversos setores estarem integrados no planejamento de ações voltadas para a sustentabilidade e democratização dos recursos naturais, colocando em prática as legislações nacionais, é fundamental que ocorra uma conscientização em massa e intensa para que a população brasileira reivindique dos seus representantes a elaboração de leis que auxiliem na execução de políticas públicas que assegurem uma melhoria na qualidade de vida e um espaço ecologicamente equilibrado e sustentável.

Importante mencionar que este estudo é de suma importância para o meio acadêmico, tendo em vista a possibilidade de desenvolvimento de outros estudos acerca de um tema tão imprescindível como o acesso a água para a garantia da vida, como também servirá de material didático para a sociedade em geral, vez que possibilitará o acesso ao leitor de material científico e que garanta possivelmente um melhor entendimento sobre o tema.

\section{Referências}

AB'SÁBER, Aziz. (2003). Os domínios de natureza no Brasil: potencialidades paisagísticas. Ateliê Editorial.

Araújo, F. V, Vianna, P. C, Souza, M. C. S, Ruffo, C. L. M. (2015). Célula de Acompanhamento e Informação o Território da Borborema-CAI. Relatório Analítico e Parcial. Campina Grande-PB. Revista Geosaberes, Fortaleza, 6(2), 168 - 177.

ASA. Articulação no Semiárido Brasileiro. (2019). Cartilha Diagnóstico de Agrossistema. Um olhar ampliado sobre a trajetória das famílias do semiárido. Disponível em: http://www.asabrasil.org.br.

ASPTA- Assessoria e Serviços a Projetos em Agricultura Alternativa. http://aspta.org.br.

Coutinho, A. A. (2010). Tecnologias sociais como instrumento de gestão participativa: a experiência da comunidade Lajedo de Timbaúba-Pb. Dissertação de Mestrado. Universidade Federal da Paraíba. João Pessoa, 145 p.

Cavenaghi, S. M., \& Alves, J. E. D. (2016). Qualidade das informações sobre fecundidade no Censo Demográfico de 2010. Revista Brasileira de Estudos de População, 33, 189-205.

Costa, E.S.T. (2013). A importância do uso das cisternas no Assentamento Oziel Pereira. Remígio-Pb. Monografia/UFPB.

Decreto No 24.643/1934 - Código das Águas. https://www2.camara.leg.br/legin/fed/decret/1930-1939/decreto-24643-10-julho-1934-498122publicacaooriginal-1-pe.html.

Decreto No 9.606/2018. http://www.planalto.gov.br/ccivil_03/_Ato2015-2018/2018/Decreto/D9606.htm\#art22.

Diniz, P. C. O. (2007). Da experimentação social ao “experimentalismo institucional”. Trajetórias de relações entre Estado e sociedade civil: experiências no Semiárido. Campina Grande (PB), Tese de Doutorado. CH-UFCG/UFPB-CCHLA/PPGS, setembro, 230 p.

Gil, A. C. Métodos e técnicas de pesquisa social. (5a ed.), Atlas, 1999.

GIL, Antônio Carlos. Métodos e técnicas de Pesquisa Social. (6a ed.), Atlas, 2000.

GONSALVES, Elisa Pereira. Conversas sobre iniciação á pesquisa cientifica. (2a ed.), Alínea (2001).

IBGE, Instituto Brasileiro de Geografia e Estatística. Censo Demográfico de 2010.

Lei 9.433/1997 - Política Nacional de Recursos Hídricos. http://www.planalto.gov.br/ccivil_03/leis/19433.htm. 
Research, Society and Development, v. 10, n. 11, e352101119719, 2021

(CC BY 4.0) | ISSN 2525-3409 | DOI: http://dx.doi.org/10.33448/rsd-v10i11.19719

Lei 12.873/2013. http://www.planalto.gov.br/ccivil_03/_ato2011-2014/2013/lei/112873.htm.

Lei 13.501/2017. http://www.planalto.gov.br/ccivil_03/_ato2015-2018/2017/lei/L13501.htm.

Lima, A. K. M., \& Sombra, D. (2018). AB'SÁBER, Aziz Nacib. Os domínios de natureza no Brasil: potencialidades paisagísticas. Ateliê Editorial, 2003. InterEspaço: Revista de Geografia e Interdisciplinaridade, 269-274.

Malvezzi, R. Semiárido: uma visão holística. Confea, 2007.

Passador, C. S, Passador, L. J., Huayta, V. R. (2010). Políticas Contra la Sequía e la Técnica de Cisterna en Brasil. Revista Agroalimentaria (Caracas), 16, $101-113$.

Paula, Thiago Rodrigo Assis. Sociedade civil e a construção de políticas públicas na região semiárida brasileira: o caso do Programa Um Milhão de Cisternas Rurais (P1MC). Revista de Políticas Públicas, 16(1), 179-189, 2012.

Piraux, M., Bonnal, P. (2007). Dinâmicas Territoriais, Projetos Coletivos e Multifuncionalidade da Agricultura Familiar na Região do Entorno de Campina Grande (Paraíba). Pesquisa e ações de divulgação sobre o tema da multifuncionalidade da agricultura familiar e desenvolvimento territorial no Brasil. Relatório 3.4, 43 p.

Projeto de Lei do Senado 111/2011. https://legis.senado.leg.br/sdleg getter/documento?dm=4068505\&ts=1594016438740\&disposition=inline.

Silva, R. M. A. (2003). Entre dois paradigmas: Combate à seca e Convivência com o semiárido. Revista Soc. estado. 181(-2).

Silva, A. A., da Silva Filha, R. T., \& Freitas, S. R. S. (2016.) Utilização de modelo didático como metodologia complementar ao ensino da anatomia celular. Biota Amazônia (Biote Amazonie, Biota Amazonia, Amazonian Biota), 6(3), 17-21.

Sachs, I. Ecodesenvolvimento: crescer sem destruir. Tradução de Eneida Araújo. Vértice, 1986.

Santos, R. P. A., Bortolin, S., \& Alcará, A. R. (2018). Técnicas de análise de dados empregadas no Programa de Pós-graduação de Ciência da Informação da Universidade Estadual de Londrina. Encontros Bibli: revista eletrônica de biblioteconomia e ciência da informação, 23(51), 59-73.

Silveira, L. M., Freire, A. G., \& Diniz, P. C. (2010). O Pólo da Borborema: ator contemporâneo das lutas camponesas pelo território. Revista Agriculturas. 7(1), 13-19. 